\title{
Chlorphentermine S.A. in the Treatment of Obesity and the Effect of Weight Loss on Steroid Excretion
}

\author{
I. M. D. JACKSON,* M.B., M.R.C.P., M.R.C.P.ED. ; W. G. WHYTE, † M.B., M.R.C.P.GLASG.
}

Brit. med. F., 1965, 2,453-455

A number of trials have been undertaken to test the efficacy of chlorphentermine (1-( $p$-chlorophenyl)-2-methyl 2-aminopropane hydrochloride; Lucofen) as an anorectic agent, and it has been shown to be superior to placebo (Lucey and Hadden, 1962 ; Levin et al., 1963). Recently a sustained-action chlorphentermine (chlorphentermine S.A.) has become available and has been used by Seaton et al. (1964) in a group of patients with " refractory obesity" as defined by Duncan et al. (1960). Their results showed a small but significant loss of weight after six weeks by patients on chlorphentermine S.A. compared with those on a dummy preparation, but thereafter the loss of weight was not significant.

For many obese patients the difficulties in losing weight by adherence to low-calorie diets are immense, and the availability of a drug which can act as an appetite suppressant would theoretically seem of advantage in such cases. In practice the anorectic agents, most of which are derived from amphetamine, have not only proved disappointing in the management of obesity but have also produced serious side-effects, including habituation and addiction (Kiloh and Brandon, 1962). Modell (1960) has suggested that the anorexigenic action of the amphetamines is closely related to their cortical excitatory action, a fact which probably accounts for their addictive qualities. Chlorphentermine differs chemically from amphetamine (see Formulae) and appears to be metabolized differently, probably owing to the para-chloro substitution; certainly neither in experimental animals (Holm et al., 1960) nor in therapeutic dosage in clinical practice (Levin et al., 1963) has chlorphentermine been reported to produce cortical stimulation.

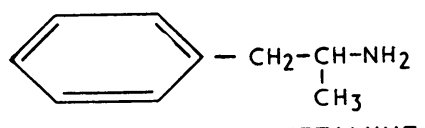

AMPHETAMINE

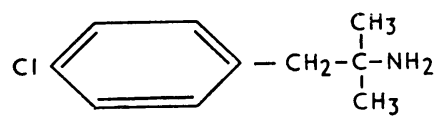

CHLORPHENTERMINE

Chemical formulae.

We herewith report a clinical trial of chlorphentermine S.A. in a group of obese patients attending an endocrine clinic. At the same time the opportunity was taken to make a number of observations on these patients, in particular their urinary steroid levels, during the course of the trial.

\section{Materials and Methods}

Forty patients (Table I) attending hospital because of obesity and overweight by at least $20 \%$ of their ideal weight (U.S.A. Medico-Actuarial Investigation, New York, 1912) were chosen for the trial. None of the patients had diabetes mellitus or clinical oedema and were not known to have any cardiac dis-

* Registrar in Endocrinology, Royal Infirmary, Glasgow.

+ Senior Registrar, Department of Endocrinology, Royal Infirmary, Glasgow. order. They were specifically questioned about any family history of diabetes or obesity. They had not previously participated in any clinical trial. A small number had been treated with anorexigenic agents by their general practitioners, but not in the previous three months.

\begin{tabular}{|c|c|c|c|c|}
\hline & & No. of Patients & Mean Age & Range of Age \\
\hline $\begin{array}{ll}\text { Male } & . \\
\text { Female } & . \\
\end{array}$ & $\begin{array}{l}\cdots \\
\cdots\end{array}$ & $\begin{array}{r}8 \\
32 \\
\end{array}$ & $\begin{array}{l}23 \text { years } \\
31 \%\end{array}$ & $\begin{array}{l}15-36 \\
17-59\end{array}$ \\
\hline Total & .. & 40 & 34 & $15-59$ \\
\hline
\end{tabular}

It was emphasized to the patients that the most important factor in their losing weight was strict adherence to their 800calorie diet and that the tablets prescribed would only help to reduce the appetite. In contrast to the method of Seaton et al. (1964) no indication was given to the patients that $50 \%$ of them would receive a placebo.

The "active" preparation consisted of a 75-mg. tablet of chlorphentermine in a sustained-release form. The placebo was comparable in appearance and taste to the test tablet and contained lactose, mannitol, starch, and a base.

The bottles each contained 28 tablets and were labelled $1-40$ by the manufacturers, who did not disclose the code until the trial had been completed. According to their order in starting the trial, the patients were randomly allocated to a particular number, for which three bottles were available, and these bottles were issued by the hospital pharmacist after each visit to the clinic. All patients were instructed to take the preparation first thing in the morning. Neither doctor nor patient was aware which type of preparation was being taken.

\section{Object and Scope of Investigation}

It was decided to compare the drug and placebo in a doubleblind manner for three months. This involved the patients returning at four-weekly intervals to be weighed, to be interviewed regarding their diet, and if necessary exhorted further regarding dietary restriction; at the same time, in accordance with their number in the trial, they were given a further bottle of tablets. The patients were not specifically questioned about side-effects beyond being asked, "How are you finding the tablets ?" Any spontaneous complaints regarding the tablets were noted.

After 12 weeks the patients were discharged for three months ; they were all told to attend their general practitioners, to whom letters were written asking them to prescribe chlorphentermine S.A. one tablet daily in the morning for three months. The patients were then told to reattend the clinic. Those who had lost more than 1 stone $(6.4 \mathrm{~kg}$.) in weight over six months were subsequently asked to report back after a further three months to assess their progress.

Before dietary and drug measures were instituted most patients had a 24-hour urine estimated for 17-ketosteroids (17-KS) and total 17-hydroxycorticosteroids (17-OHCS) (Few, 1961), and this was repeated after three months on the trial. Any striae or hirsutism in these patients were noted. 


\section{Results}

The initial weights of the two groups of patients are comparable. The changes in weight are set out in Table II. After one month the difference between the two groups was not quite significant; after two months the difference was just significant, and by the completion of three months on the trial the difference between the two groups was significant at $\mathrm{P}<0.02$, the loss of weight at this time of those on the test preparation being $13.9(+4.7)$ lb. $(6,305 \pm 2,130$ g.) compared with 4.6 $( \pm 2.2)$ lb. $(2,085 \pm 998 \mathrm{~g}$. $)$ of those on the placebo.

TABLE II.-Weight Loss of the Two Groups of Patients in Pounds (Values are Means and Standard Deviations)

\begin{tabular}{|c|c|c|c|c|c|}
\hline \multicolumn{3}{|c|}{ Time } & \multirow{2}{*}{$\begin{array}{r}\text { Test Group } \\
5 \cdot 7 \pm 1 \cdot 7 \\
10 \cdot 0 \pm 2 \cdot 1 \\
13 \cdot 8 \pm 2 \cdot 4\end{array}$} & \multirow{2}{*}{$\begin{array}{c}\text { Placebo Group } \\
\begin{array}{c}1 \cdot 5 \pm 1 \cdot 6 \\
2 \cdot 8 \pm 2 \cdot 0 \\
4 \cdot 6 \pm 2 \cdot 2\end{array}\end{array}$} & \multirow{2}{*}{$\begin{array}{c}\begin{array}{c}\text { Analysis of } \\
\text { Difference } \\
\text { Between Groups }\end{array} \\
0.05<\mathrm{P}<0.1 \\
0.02<\mathrm{P}<0.05 \\
0.01<\mathrm{P}<0.02\end{array}$} \\
\hline $\begin{array}{c}\text { After } 1 \\
\Rightarrow \quad 2 \\
, 3\end{array}$ & $\begin{array}{l}1 \text { month } \\
2 \text { months } \\
3 \text {, }\end{array}$ & $\begin{array}{l}\ldots \\
\cdots\end{array}$ & & & \\
\hline$\Rightarrow 6$ & 6 & $\ldots$ & $13 \cdot 9 \pm 4 \cdot 7$ & $7 \cdot 8 \pm 4 \cdot 4$ & $0.3<P<0.4$ \\
\hline
\end{tabular}

The mean loss of weight of those patients on the active preparation and then given chlorphentermine S.A. for a further three months did not alter. The placebo group subsequently given chlorphentermine S.A. for a further three months increased their mean loss of weight to $7.8 \mathrm{lb}$. $(3,540 \mathrm{~g}$.). The difference between the loss of weight of the two groups is no longer significant owing to the wide scatter of results at this time.

The urinary steroid estimations are shown in Table III. For the total number of patients (men and women) the level of $17-\mathrm{KS}$ fell not quite significantly $(P=0.06)$ over the first three months, whereas the level of total 17-OHCS fell just significantly $(\mathbf{P}=0.03)$ over the same period. The weight loss is positively correlated with both the fall in level of $17-\mathrm{KS}$ and fall in level of 17-OHCS, but not significantly so.

TABLE III.-Urinary Steroid Excretion in mg./24 hours (Values are Means and Standard Deviations)

\begin{tabular}{|c|c|c|c|c|c|c|}
\hline & & & \multicolumn{2}{|c|}{ Initially } & \multicolumn{2}{|c|}{ After 3 Months } \\
\hline & & & $17-\mathrm{KS}$ & $\begin{array}{c}\text { Total } \\
\text { 17-OHCS }\end{array}$ & $17-\mathrm{KS}$ & $\begin{array}{c}\text { Total } \\
\text { 17-OHCS }\end{array}$ \\
\hline $\begin{array}{l}\text { Men } . . \\
\text { Women } . .\end{array}$ & $\because$. & $\therefore$ & $\begin{array}{l}13.6 \pm 2 \cdot 1 \\
10 \cdot 8 \pm 0.7\end{array}$ & $\begin{array}{l}21 \cdot 2 \pm 3 \cdot 8 \\
14 \cdot 6 \pm 1 \cdot 0\end{array}$ & $\begin{array}{l}9 \cdot 7 \pm 1 \cdot 0 \\
9 \cdot 4 \pm 0.9\end{array}$ & $\begin{array}{l}21 \cdot 5 \pm 3 \cdot 6 \\
12 \cdot 5 \pm 1 \cdot 2\end{array}$ \\
\hline \multicolumn{3}{|c|}{ Total (men and women) } & $11 \cdot 3 \pm 0 \cdot 7$ & $16 \cdot 0 \pm 1 \cdot 2$ & $9 \cdot 5 \pm 0.7$ & $14 \cdot 7 \pm 1 \cdot 4$ \\
\hline
\end{tabular}

There were six women who were "obese with striae" (Summers et al., 1964), but their steroid excretion did not differ significantly from the whole group. Five of the eight males had striae, and their mean 17-OHCS excretion was elevated compared with the other three who did not have striae.

Ten patients $(25 \%)$ gave a family history of diabetes mellitus in a near relative, and half of the patients in the trial had one or more near relatives who were obese. There was no apparent relation between a high initial level of $17-\mathrm{KS}$ or total $17-\mathrm{OHCS}$ and a family history of diabetes or obesity.

At the end of three months and six months there was no significant difference in terms of weight loss between men and women, between women under and over 40 years of age, and between those who had a family history of diabetes or obesity and those who did not.

Defaulters.-After three months 10 patients had defaulted in spite of having agreed to attend the clinic regularly prior to being admitted to the trial. Of the 10 five had been on chlorphentermine S.A. and five on placebo. After six months only 24 patients were left in the trial, six further patients either not receiving the correct tablets from their general practitioner or not taking them as prescribed.

Side-effects.-The incidence of side-effects in those taking chlorphentermine S.A. was $13(65 \%)$ compared with four
$(20 \%)$ for the placebo. The most common complaints of the chlorphentermine patients were nausea with or without headaches and dizziness. In addition to nausea one patient had vomiting and one had dryness in the back of the throat. Other complaints noted were diarrhoea in one patient and "a lump in the back of the throat" in one patient. The complaints of those on placebo were " nervous rash," nausea, dizziness, and constipation. No patient withdrew from the trial as a result of side-effects from the tablets. The gastro-intestinal complaints of those on chlorphentermine S.A. occurred usually in the first month and gradually wore off, ceasing to be troublesome. In a few instances the patients stopped the tablets for two or three days before resuming them again.

Patients Seen After Nine Months.-Ten patients who had lost more than 1 stone $(6.4 \mathrm{~kg}$.) in weight by six months were recalled three months later. Eight patients attended, and of these three had continued to lose weight $(3,3$, and $8 \mathrm{lb}$. $(1,360$, 1,360 , and 3,630 g.) respectively), three had remained at the same weight, and two had put on weight ( 3 and $11 \mathrm{lb}$. $(1,360$ and 4,990 g.) respectively). Only four patients still continued to take chlorphentermine, and three of these had lost weight and one had remained steady.

\section{Discussion}

It is not easy to design an ideal clinical trial for an appetite suppressant. We have tested chlorphentermine S.A. not only in a double-blind trial with all the aura of frequent hospital attendances and mystery bottles with coded numbers, but also in the more mundane manner of asking the general practitioner to write out a prescription for some " pill." In the context of a hospital clinic in which repeated doses of encouragement and explanation of dietary principles are given at frequent intervals, chlorphentermine S.A. is shown to be more efficient than a placebo in catalysing loss of weight over a period of three months. However, away from the influence of the four-weekly attendance at a special clinic, so-called adherence to dietary measures plus chlorphentermine S.A. produced no significant loss of weight. Seaton et al. (1964) found in their patients that chlorphentermine S.A. was effective as an anorectic only in the first six weeks of being prescribed, after which it ceased to be effective. Under clinical trial conditions we have found it to be effective for three months, but an increased tolerance to the drug could be a factor in the lack of further response in the test group of patients. However, in the placebo group of patients chlorphentermine S.A. did not produce any significant loss of weight in the second three-monthly period, the mean weight loss during this period being $3.2 \mathrm{lb}$. (1,450 g.) compared with $4.6 \mathrm{lb}$. $(2,085 \mathrm{~g}$.) while on the dummy preparation.

The incidence of a family history of diabetes or obesity was high, but this was found to bear no relation to subsequent loss of weight ; nor was any effect determined by the initial level of $17-\mathrm{KS}$ and total $17-\mathrm{OHCS}$.

After dieting for three months both the 17-KS and total 17-OHCS levels in the urine fell, the latter falling significantly. The fall in urinary steroid excretion correlated with loss of weight, but not statistically $(P>0.05)$. Cohen (1958) found a decrease in urinary steroid excretion in obese children placed on low-calorie diets and suggested that over-nutrition may produce functional hyperpituitarism or hyperadrenocorticism or both. Simkin (1961) also found in 10 out of 15 adult obese patients a significant fall in steroid excretion in the early stages of weight reduction.

Side-effects from chlorphentermine S.A. were common but not especially troublesome. Certainly no evidence of cortical stimulation was observed. The nausea which was particularly noticeable initially became less of a problem if the patient persisted with the preparation. The manufacturers recommend chlorphentermine S.A. to be taken after breakfast, and adherence 
to this may cause less gastro-intestinal disturbance. The sideeffects of chlorphentermine S.A. may not, however, be entirely local in action, and it is possible that the anorectic action of chlorphentermine may be dependent on its function as a mild central emetic at medullary level. The 10 defaulters up to three months contained five on the test preparation and five on the placebo, so that it seems unlikely that the default rate was related to the gastro-intestinal effects of chlorphentermine.

As a result of this investigation what conclusions can be drawn regarding chlorphentermine S.A ? It would appear to be of value as a supplement to the treatment of obesity, in which close medical supervision and encouragement of strict dietary measures are the mainstay of therapeutic management. By itself the drug has no definite role. It is recognized that the doctor often feels the need to prescribe an appetite suppressant for his obese patient who complains of excess appetite and requests a "slimming pill," and in such circumstances chlorphentermine S.A. may be useful, since it is an anorectic but does not act as a cerebral stimulant.

\section{Summary}

A clinical trial on the anorectic agent chlorphentermine S.A. was performed. The drug was shown to be of value as an adjunct to dietary measures in producing loss of weight in obese patients attending a hospital clinic at regular intervals for three months. However, these patients who were subsequently prescribed the drug by their general practitioners showed no significant loss of weight over a similar period of time.
There was a strong family history of diabetes and obesity, but this bore no relation to subsequent loss of weight.

After three months' dieting the mean total 17-OHCS and $17-\mathrm{KS}$ fell, the former significantly. The fall in urinary steroid excretion correlated with the loss of weight, but not statistically so.

The value of chlorphentermine S.A. and the indications for its use are discussed.

We should like to thank Dr. E. G. Oastler for advice and criticism ; Dr. J. K. Grant for the steroid assays ; and Mr. M. W. Birch, Department of Mathematics, University of Glasgow, for help with the statistics.

The long-acting chlorphentermine preparation (Lucofen SA) and identical placebo tablets were provided by Wm. R. Warner and Co. Ltd.

\section{REFERENCRS}

Cohen, H. (1958). Brit. med. F., 1, 686.

Duncan, L. J. P., Rose, K., and Meiklejohn, A. P. (1960). Lancet, 1, 1262 .

Few, J. D. (1961). F. Endocr., 22, 31.

I.m, T., Huus, I., Kopf, R., Møller Nielson, I., and Petersen, P. V. (1960). Acta pharmacol. (Kbh.), 17, 121.

Kiloh, L. G., and Brandon, S. (1962). Brit. med. F., $2,40$.

Levin, J., Trafford, J. A. P., Newland, P. M., and Bishop, P. M. F. (1963). Practitioner, 191, 65

Lucey, C., and Hadden, D. R. (1962). Ulster med. 7., 31, 181

Modell, W. (1960). F. Amer. med. Ass., 173, 1131 .

Seaton, D. A., Rose, K., and Duncan, L. J. P. (1964). Practitioner, 193 698.

Simkin, B. (1961). New Engl. 7. Med., 264, 974.

Summers, V. K., Sheehan, H. L., Hipkin, L. J., and Davis, J. C. (1964). Lancet, 2 , 1079 .
This paper frequently refers to three concepts-a mucosal abnormality, a clinical picture, and a disease entity. The clinical picture is described in a separate communication

* St. Thomas's Hospital, London.
(Hindle and Creamer, 1965) and corresponds closely to the experience of other workers. The mucosal abnormality and the disease entity, however, have been variously named, often implying slightly different definitions. In order to avoid confusion our use of terms is described.

Mucosal abnormality.-This is a structural alteration which is universally accepted when gross but has no absolute endpoint. Shiner and Doniach (1960) introduced the terms subtotal and partial villous atrophy to describe the complete or partial loss of villi, and Holmes et al. (1961b) later showed that each corresponded to a dissecting-microscope appearance, a flattened surface in subtotal and a convoluted appearance in partial villous atrophy. The difficulty is that some workers appear to include rather minor abnormalities under partial villous atrophy, and also that other conditions may produce a convoluted appearance (Creamer, 1964a). In our opinion a distinction is usually easy if attention is paid not only to the structure but also to the presence of chronic inflammatory cells in the stroma and degenerative changes in the surface epithelium with lymphocytic infiltration. Most of the cases described here had a flattened appearance on examination with the dissecting microscope, and all showed the changes of inflammation and epithelial degeneration. This we call a flat mucosa.

Disease entity.-Under the labels of idiopathic steatorrhoea, adult coeliac disease, and non-tropical sprue, a disease is recognized which may be linked with coeliac disease of childhood 